This situation was considered unsatisfactory; therefore, the Pyhäjoki Health Station, the Local Branch of Finnish Red Cross in Pyhäjoki, the Fire Station, and Life-Boat Association of Pyhäjoki jointly established a local first-responder unit on 16 June, 1996. The purposes of this unit are to: 1) begin life-saving treatment of emergency patients sooner; 2) prepare the patient for transport using the paramedics' ambulance; and 3) assist the paramedics with their duties. During the office hours of the Health Station, the first-response group (Group 1) consists of one doctor, two nurses, and two firemen. Outside the office hours, the group (Group 2) consists of two members of the local branch of Red Cross, one of whom must be a health-care professional, while the other can be a layman who must have been trained in basic first response. Furthermore, the group also includes 2-3 firemen, who also must have been trained as first responders. Both groups can be alerted for emergencies by the emergency services dispatch centre persons who seems to be at high risk. The Health Station is responsible for providing the groups with paramedics' equipment and medicine, supplies, and for maintenance and replacement of these materials. The fire station gives pagers to the group members and provides them with a vehicle complete with first-aid and communication equipment. When necessary, the LifeBoat Association of Pyhäjoki provides the group with sea transportation. The Red Cross regularly trains this emergency unit. The responsible doctor from the Health Station supervises the operations.

In 1997, the first-responder unit was alerted 34 times and 38 patients were evaluated. The alerts consisted of seven accidents and 27 attacks of illnesses. According to the final evaluations, three of the accidents, and 14 of the illness cases required emergency care. Emergency group 1 reached the scene approximately 11 minutes (range: 2-18 min.) before the ambulance, and group 2 on the average 8 minutes (range: $0-20 \mathrm{~min}$.) before the ambulance. After the first 1.5 years experience, the cooperation between officials and volunteers has been working very well.

Key words: firefighters; first-responder unit; health station; paramedic; prehospital emergency care; Red Cross

\section{The Quality of Paramedical Treatment for Emergency Patients in Raahe Area Arkko P, Aunola A}

Joint Municipal Authority of Health Care in the Raahe Area, Raahe, Finland

The quality of paramedical treatment received by emergency patients in the area of five municipalities and $34 ; 400$ inhabitants was measured by studying how the paramedic treatment reports had been filled in, how quickly the patients had been reached, and what had been the immediate result of the treatment. The 185 emergency patients from the five Raahe-area municipalities, who were treated by the three private paramedic units in 1995 and 1996, were studied. Patients who had suffered from disorders in the basic life functions of respiration, blood circulation, or consciousness were classified as emergency patients.

During the study period, the paramedic units responded to a total of 5,632 cases. Of these, $7 \%$ of the paramedic reports showed the time when the emergency call had been received in the emergency services dispatch centre. In $100 \%$ of the cases, the time of the ambulance receiving the alert had been recorded, and $42 \%$ of the reports noted the time of that the ambulance arrived on the scene. In $83 \%$ of the cases, the time that the attendants reached the patient had been recorded, and $34 \%$ of the reports also contained the starting time of the transportation. In $29 \%$ of the reports, the patient's arrival time at the hospital was recorded, and $62 \%$ of the records contained the ending time of the whole emergency process. There were no records of the alert or transportation codes. Information that described the paramedical treatment on the scene and during the transport could be reconstructed for $83 \%$ of the cases.

The median values for the time in minutes to reach the patient within the area of the municipalities were the following: Raahe, 8 (range: 1-30); Pattijoki, 10 (range: 3-20); Ruukki, 10 (range: 4-38); Siikajoki, 21 (15-27); and Pyhäjoki, 23 (10-35). The paramedics reached the patients within 10 minutes in $58 \%$ of the cases. The corresponding 10 minute proportions for the member municipalities were: Raahe, 77\%; Ruukki, 67\%; Pattijoki, 57\%; Pyhäjoki, 4\%; and Siikajoki, $0 \%$. A total of $47 \%$ of the patients had benefitted directly from the treatment provided. There were 41 attempted resuscitations, $59 \%$ of which were successful in the emergency situation. Of all the paramedic reports, $12 \%$ lacked sufficient information to the extent that the results of the paramedic treatment could not be evaluated.

This study revealed deficiencies in supervision and feedback in the emergency medical services system as well as regional inequalities in the paramedic services within the Raahe area.

Key words: medical records; outcome; paramedic; prehospital emergency care; response times

\section{Specialization and Increasing Medical Abilities and Facilities Under Overwhelming Situations of Different Scale in Siberia}

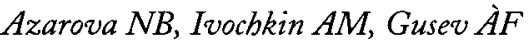

Siberian Center for Disaster Medicine, Novosibirsk, Russia

The presence of potentially dangerous objects (chemicals, hazardous environments, etc.) with the likelihood of the primary striking each administrative territory of Siberia determines the particular specialization of Disaster Medicine for the area. For instance, Disaster Medicine of Ôimsk area pays greater attention to preparing the ability and facilities to manage the consequences the release of radiation; in Kemerovo area, minor trauma (polytraumas), barotrauma, and the crush syndrome; in the Omsk area, chemical releases; and so on.

Disaster Medicine ensures treatment during the 